BMJ Open Sport \& Exercise Medicine

\title{
Virtual sports deserve real sports medical attention
}

\author{
Ana Monteiro Pereira (D) ,1,2 João Brito, ${ }^{1}$ Pedro Figueiredo, ${ }^{1,2}$ Evert Verhagen (D) ${ }^{3,4}$
}

To cite: Pereira AM, Brito J, Figueiredo $\mathrm{P}$, et al. Virtual sports deserve real sports medical attention. BMJ Open Sport \& Exercise Medicine 2019;5:e000606. doi:10.1136/ bmjsem-2019-000606

\section{Check for updates}

(c) Author(s) (or their employer(s)) 2019. Re-use permitted under CC BY-NC. No commercial re-use. See rights and permissions. Published by BMJ.

'Portugal Football School Portuguese Football Federation, Oeiras, Portugal

${ }^{2}$ Health Sciences and Human Development, Research Center in Sports Sciences, CIDESD, University Institute of Maia, ISMAI, Maia, Portugal ${ }^{3}$ Public and Occupational Health, Amsterdam Movement Sciences, Amsterdam Collaboration for Health and Safety in Sports, Amsterdam UMC, Vrije Universiteit Amsterdam Amsterdam, The Netherlands ${ }^{4}$ Human Biology, UCT/MRC Research Unit for Exercise Science and Sports Medicine (ESSM), Cape Town, South Africa

Correspondence to Ana Monteiro Pereira; ana.pereira@fpf.pt

\section{ABSTRACT}

In recent years, virtual sports or 'eSports' have grown exponentially both recreationally and at the professional level. eSports comprise several regulated video games played competitively, using electronic platforms. Some eSports competitions present a structure comparable to traditional sports, and eSports players, even with major skills and mental focus, need preparation and training to thrive. However, little is known about the demands of eSports competitions and continuous training. As the popularity and stakes rise, concerns about the health and emerging risks of eSports participation might arise. Indeed, in the absence of proper descriptive data about the specific characteristics of the eSports population (including factors such as screen time, physical activity, overuse injuries or training environment), effective prevention and care cannot be developed nor provided. Therefore, quality healthcare and prevention strategies are needed. In the current viewpoint, we argue that those involved with Sports Science and Medicine should lead the discussion and reflect on the health effects of eSports participation, providing scientifically-based arguments to better answer to the current eSports professionalism.

In our contemporary society, there is an increasing concern about screen time and the potential adverse effects this has on short-term and long-term health. ${ }^{1}$ The World Health Organisation (WHO) has already released guidelines on physical activity, acknowledging the risk associated with sedentary behaviour. However, guidelines that mention screenbased sedentary activities are available for children only. Have you ever considered that screen time might be synonymous with time spent on sports?

Sports can be defined as a game, competition or activity needing physical effort and skill that is played or done according to rules, for enjoyment and/or as a job. ${ }^{2}$ The Australian Bureau of Statistics adds that sports are activities 'involving physical exertion, skill and/or hand-eye coordination as the primary focus of the activity, with elements of competition where rules and patterns of behaviour governing the activity exist formally through organisations'. ${ }^{3}$ Therefore, sports practice might include almost any kind of physical activity or exercise, and it is influenced by different contexts and individual disposition. On the other hand, there is still no consensual definition for eSports. Generally, eSports comprise a number of different video game modalities, played competitively on controlled environments, with structure and regulations similar to traditional sports (eg, leagues, ladders and tournaments) ${ }^{4-7}$ There are different eSports categories, like Sports (eg, FIFA EA SPORTS), Firs-Person-Shooter (eg, Call of Duty), Battle Royal (eg, Fortnite), Strategy (eg, Starcraft) and Multiplayer Online Battle Arena (eg, League of Legends).

Over the past decade, eSports have grown exponentially and now also reaches competitively into the realm of traditional sports. Several professional eSports competitions have emerged to a similar structure (figure 1), popularity (figure 2) and revenue (figure 3) as professional sports. For instance, FIFA recently introduced the FIFA eNations Cup that took place in England, where 16 national teams representing all of FIFA's confederations competed against each other. The nations themselves hosted national virtual football championships to find their national team and selected two players who represented their country at the FIFA eNations Cup. The French team-with the players 'Maestro' and 'DaXe'-was the inaugural winner of this tournament.

\section{A LEGITIMATE SPORT?}

This is a question under contemporary academic deliberation and without a definite answer so far. ${ }^{58}$ The International Olympic Committee also held a debate to discuss precisely this question. ${ }^{9}$ The outcome was that competitive eSports, although not in line with the rules and regulations of the Olympic movement, could be considered a sporting activity while the players involved prepare and train with an intensity that could be comparable to athletes in traditional sports. This statement recognised the high skill, dexterity and mental focus required to compete in eSports at a professional level. However, the literature is still scarce and conflicting results 


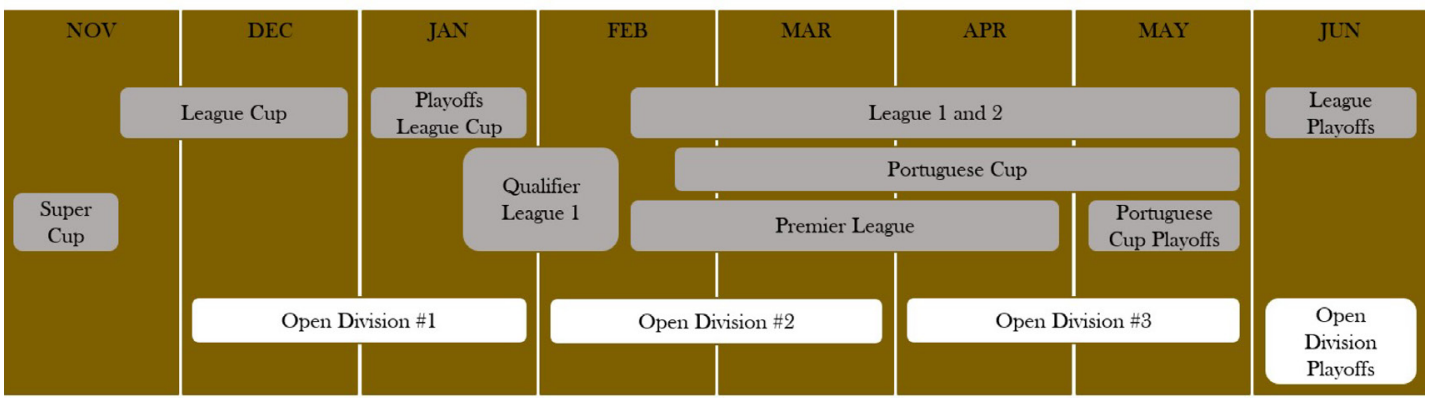

Figure 1 Set-Up of the virtual football (EA SPORTS FIFA19) 2018-2019 season for clubs, as organised by the Portuguese Football Federation.

on the physiological impact (ie, heart rate, blood pressure and perceived stress) of eSports practice have been reported (Leis O. Stress in Esports: A Systematic Literature Review-Halle, Germany 2019).

Rudolf and colleagues, (personal communication: Stress im eSport-Ein Einblick in Training und Wettkampf. eSport Konferenz 'Professionalisierung einer Subkultur?'-Bayreuth, Germany 2016) in a very small study involving five male Counter Strike players found that the acute stress measured through cortisol levels and heart rate were comparable with those found in elite athletes from other sports. As such, without answering the question of whether we are dealing with a legitimate sport, future studies on elite eSport participants should focus on training effort and competition stress experienced by the athletes. ${ }^{3}$ Undeniably, eSports are part of contemporary culture. Likely, we have only witnessed the start of this movement to date. With the increasing popularity and high stakes (figures 2 and 3), the professionalism of eSports will continue to rise. This begs the rhetorical question, with competition already at a high level, whether Sports and Exercise Medicine could provide quality care and health protection for eSports professional players. The available evidence to do so is 'thin', and a big push is required to get up to speed. ${ }^{10}$

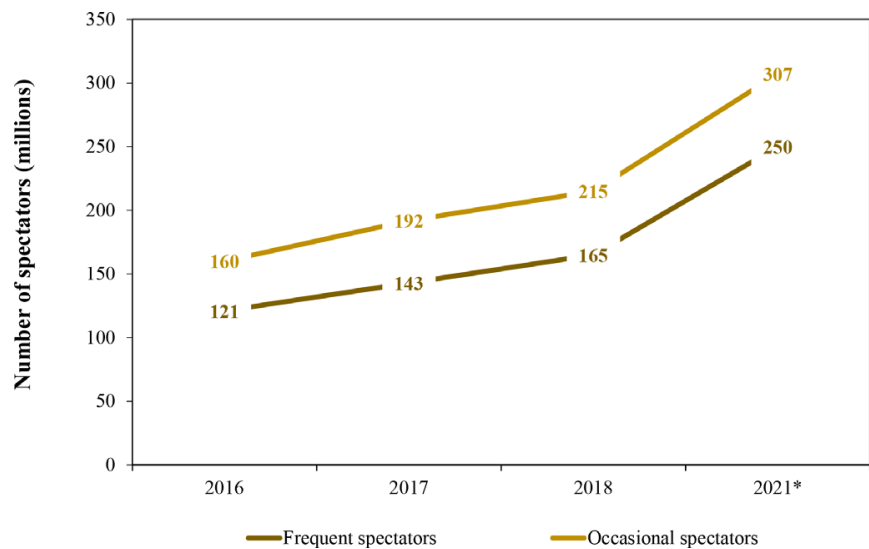

Figure 2 Global overview of eSports spectators (in millions of people). Historical information and projection* based on data retrieved online from: https://www.wepc.com/news/ video-game-statistics/; and NewZoo, free 2018 global eSports market report, 2018.
Therefore, in this viewpoint, we propose some topics that should be addressed initially to provide a baseline for quality sports medical care in eSports.

\section{A SEDENTARY ATHLETE?}

It has been scientifically underpinned that sedentary time, although attenuated by physical activity levels, is associated with negative long-term health. ${ }^{11}$ It is an ecological fallacy to believe the eSports athlete is similar to the general inactive youth population as described in public health research. For example, exergames combine video gaming and exercise, as they use movement as an interface with the game itself, promote maintenance and improvement of physical status. ${ }^{12}$ Also, a recent cross-sectional survey among 928 virtual football players (mean age of $24 \pm 6$ years old, $99 \%$ men) registered with the Portuguese Football Federation (FPF) showed that $79 \%$ of the 721 valid responders performed regular physical training. ${ }^{13}$ Interestingly, $73 \%$ reported having high levels of physical activity and performed vigorous-intensity activity at least 3 days a week achieving a minimum of 1500 MET-minutes/ week or performing any combination of exercise on $\geq 7$ days a week, that takes at least 3000 MET-minutes/

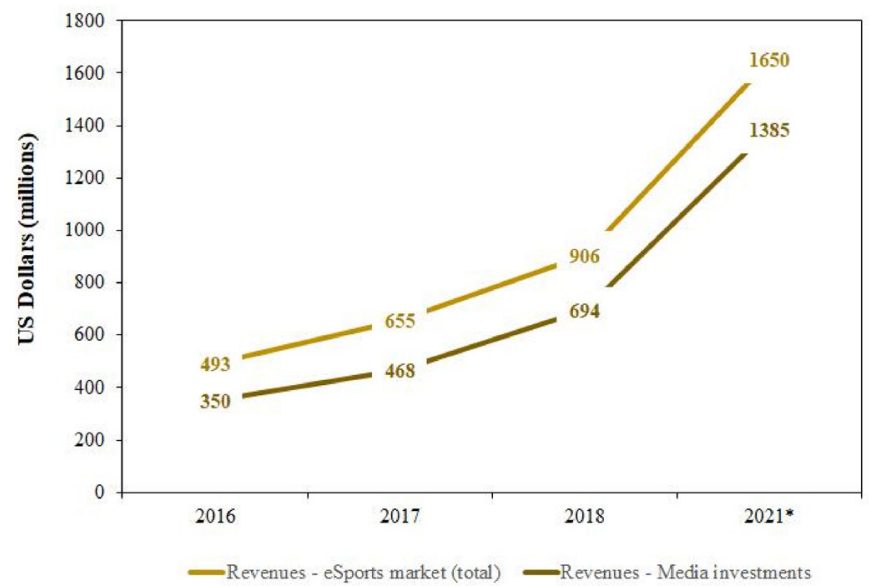

Figure 3 Global overview of eSports revenues (in millions of USD). Historical information and projection* based on data retrieved online from: https://www.wepc.com/news/videogame-statistics/; https://www.mmogames.com/wp-content/ uploads/2018/05/2017-video-game-trends-and-stats-1.png; and NewZoo, free 2018 global eSports market report, 2018. 


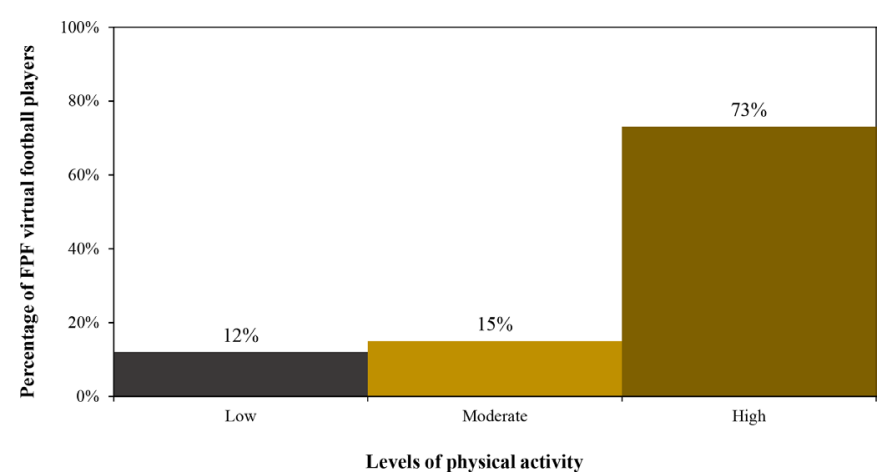

Figure 4 Levels of physical activity based on IPAQ survey data of virtual football players registered with the Portuguese Football Federation and participating in official eSports competitions $\left(n=721 ; \chi^{2}=499.52 ; p<0.01\right) .{ }^{13}$

week (figure 4), which is above the recommended levels by the WHO Guidelines for Physical Activity. ${ }^{14}$ Similar conclusions were drawn in a study conducted in Finland on elite eSports athletes (mean age: $29 \pm 4$ years old, $97 \%$ men), with the participants reporting physical activity exceeding three times those recommendations. Overall, this implies we are dealing with a specific demographic, and we require a better understanding of who these individuals are and how short-term and long-term health is affected by sedentary time in the eSport population.

In addition, general adverse health effects of a high amount of screen time may be prevalent in eSport athletes. ${ }^{15}$ Increased screen time is associated with detrimental effects on sleep, psychological state, petulance and cognitive and socioemotional development. Also, there is a risk of musculoskeletal complaints due to repetitive fine motor strain through computer use. In the absence of proper descriptive data on such general symptoms in the specific eSports population, effective prevention and care cannot be developed nor provided.

\section{THE DEMANDS OF ESPORTS COMPETITIONS}

We know little to nothing about the psychological and physiological demands of the various eSports competitions, nor how the psychological and physical health of these athletes are affected in the short and long terms. Although only cross-sectional in nature, a recent study on 65 collegiate eSport players from nine universities across the USA and Canada reported that eSport players are susceptible to overuse injuries, with asthenopia (eye fatigue), neck pain and back pain being the most prevalent injuries. ${ }^{15}$ These injuries are arguably logical; eSports practice could mimic some negative features of other occupations that require long periods using computers and consoles (eg, administrative professionals, technology jobs, transportation careers, blue-collar workers), repetitive or forceful movements, awkward and static postures, poor lighting environments and prolonged sitting in the same position. All of which are physical causes and risk factors associated with described poor work-related health outcomes. ${ }^{16}$

\section{COMPETITION PRESSURE ON THE RISE}

With an increase in competitive stakes, the influence of competition on professional eSports is likely to increase in the near future, and with our current lack of knowledge, we are ill-prepared for this looming development. First, with the increased social and media impact of eSports and the rise of competition rewards or sponsorship, the pressure for a better performance probably will rise. Even with extended research related to supplements use on high-performance athletes, such as adverse effects, safety and composition, ${ }^{17}$ there is no scientific information base on substances used by eSports players at high levels nor the health consequences of their use. Second, this pressure could predispose eSports players to experience anxiety or other mental problems. Recently, the International Classification of Diseases-11th revision (ICD-11) included for the first time the 'gaming disorder' in the group of 'disorders due to addictive behaviours'. eSports practice might be associated with this disorder, but, as stated by the WHO, 'studies suggest that gaming disorder affects only a small proportion of people who engage in digital- or video-gaming activities'. ${ }^{19}$ This severely hampers our ability to know better and improve preparation strategies for eSports athletes before competition and to protect their health through a competitive season.

Still, it should be noted that despite some eSports clubs are already paying salaries to eSports players, the prize money of eSports tournaments is the primary method for acquiring financial security for the participants themselves. Professional eSports players might be just a small number of the thousands of participants regularly engaged with eSports, ${ }^{20}$ but with the expected growth of professional eSports players, also grows the necessity to better understand their 'work' environment and potential emerging risks, to better anticipate and prevent negative health outcomes.

\section{THE ROLE OF SPORTS AND EXERCISE MEDICINE IN ESPORTS}

eSports is booming and there is an increase in competitiveness and professionalisation, yet little is known about how to train and prepare best for eSports. Just like any other professional athlete, an eSports athlete deserves our best care. For that, it is us-those involved with Sports and Exercise Medicine-who should lead the discussion and reflect on the health of eSports athletes. After all, without a doubt, eSports have entered our realm, so we need to be proactive in gaining an understanding of this contemporary phenomenon and we must face this new reality with scientifically-based arguments to be prepared for professionalism of eSports.

\section{Twitter Evert Verhagen @evertverhagen}

Contributors All authors contributed to this editorial. EV and AMP wrote the initial draft and revisions of subsequent texts. JB and PF provided the idea and feedback to the drafts. All authors have read and commented on the draft version and approved the final version of the manuscript.

Funding The authors have not declared a specific grant for this research from any funding agency in the public, commercial or not-for-profit sectors. 
Competing interests None declared.

Patient consent for publication Not required.

Provenance and peer review Not commissioned; externally peer reviewed.

Open access This is an open access article distributed in accordance with the Creative Commons Attribution Non Commercial (CC BY-NC 4.0) license, which permits others to distribute, remix, adapt, build upon this work non-commercially, and license their derivative works on different terms, provided the original work is properly cited, appropriate credit is given, any changes made indicated, and the use is non-commercial. See: http://creativecommons.org/licenses/by-nc/4.0/.

\section{ORCID iDs}

Ana Monteiro Pereira http://orcid.org/0000-0002-0495-9230

Evert Verhagen http://orcid.org/0000-0001-9227-8234

\section{REFERENCES}

1 Stiglic N, Viner RM. Effects of screentime on the health and wellbeing of children and adolescents: a systematic review of reviews. BMJ Open 2019:9:e023191.

2 Cambrigde Online Dictionary. Meaning of sport in English. Available: https://dictionary.cambridge.org/dictionary/english/sport [Accessed Sep 2019].

3 Pink B. Defining sport and physical activity, a conceptual model. Statistics ABO, 2008

4 Karhulahti V-M. Reconsidering Esport: economics and executive ownership. Physical Culture and Sport Studies and Research 2017;74:43-53.

5 Hallmann K, Giel T. eSports - competitive sports or recreational activity? Sport Management Review 2018;21:14-20.

6 McCutcheon C, Hitchens M, Drachen A. eSport vs irlSport. Advances in computer entertainment technology, 2018: 531-42.

7 Hamari J, Sjöblom M. What is eSports and why do people Watch it? Internet Research 2017;27:211-32.
8 Pluss MA, Bennett KJM, Novak AR, et al. Esports: the chess of the 21st century. Front Psychol 2019;10:339-10.

9 International Olympic Committee. Communique of the 7th Olympic Summit, 2018. Available: https://www.olympic.org/news/ communique-of-the-7th-olympic-summit [Accessed May 2019]

10 Steinkuehler C. Empirical, and historical studies of competitive Videogame play. Games Cult 2019;86:1-6.

11 Ekelund U, Brown WJ, Steene-Johannessen J, et al. Do the associations of sedentary behaviour with cardiovascular disease mortality and cancer mortality differ by physical activity level? A systematic review and harmonised meta-analysis of data from 850 060 participants. Br J Sports Med 2019;53:886-94.

12 Bamparopoulos G, Konstantinidis E, Bratsas C, et al. Towards exergaming commons: composing the exergame ontology for publishing open game data. J Biomed Semantics 2016;7:4

13 Pereira AM, Figueiredo P, Brito J, et al. Evaluation of physical activity levels in FPF eSports e-athletes. Motricidade 2019;15.

14 Kari T, Karhulahti VM. Do E-Athletes move?: a study on training and physical exercise in elite E-Sports. Int J Gaming Comput Mediat Simul 2016;8:53-66.

15 DiFrancisco-Donoghue J, Balentine J, Schmidt G, et al. Managing the health of the eSport athlete: an integrated health management model. BMJ Open Sport Exerc Med 2019;5:e000467-6.

16 European Agency for Safety and Health at Work. Musculoskeletal disorders, 2018. Available: https://osha.europa.eu/en/themes/ musculoskeletal-disorders [Accessed May 2019].

17 Maughan RJ, Burke LM, Dvorak J, et al. IOC consensus statement: dietary supplements and the high-performance athlete. Br J Sports Med 2018;52:439-55.

18 World Health Organization. ICD-11 for mortality and morbidity statistics: 6C51 gaming disorder. version: 04, 2019. Available: http:// id.who.int/icd/entity/1448597234

19 World Health Organization. Gaming disorder 2018, 2018. Available: https://www.who.int/features/qa/gaming-disorder/en/

20 Brock T. Roger Caillois and E-Sports: on the problems of treating play as work. Games Cult 2017;12:321-39. 